Brit. F. vener. Dis. (1967), 43, 18.

\title{
THE OLD MORALITY* $†$ \\ A STUDY OF SEROLOGICAL TESTS FOR VENEREAL INFECTION IN ELDERLY PEOPLE
}

\author{
BY \\ J. G. PRITCHARD , A. M. MECHIE $\ddagger$, AND J. G. McHUGH \\ Foresthall Hospital, Glasgow \\ AND \\ P. A. BOOT, F.I.M.L.T.ף \\ Stobhill General Hospital, Glasgow
}

Serological tests for venereal infection have been performed routinely on all admissions to Foresthall Hospital, a Geriatric Unit of 550 beds, for the last 3 years (1963-5 inclusive). An earlier study from the Unit (Gibson and Pritchard, 1965) showed a surprisingly large proportion of positive tests for venereal disease among elderly patients. This present study was designed to examine further this aspect of morbidity in the elderly. A retrospective study was undertaken on 1,529 cases (929 males and 600 females). Observations were taken for demographic data, serological investigations, the history of venereal infection, if inquired for, and whether treatment was given. Clinical evidence of syphilis was noted as was any relevant investigation. We found that the history of infection was not a constant question in case interrogation and the paucity of information obtained eliminated this facet from the investigation. Over the period of the survey Foresthall Hospital had about half of the total beds allocated for geriatric purposes in the City of Glasgow. Though there was no bias against any particular section of the community, Foresthall Hospital by policy offers priority of admission to 609 residents in the adjacent Local Authority section of the institution, who may fall ill. This, and the fact that Glasgow is mainly an industrial city and sea-port, introduces known features into this study.

\footnotetext{
* Part of this article formed the basis of a lecture to the British Geriatrics Society at Edinburgh on April 15, 1966.

† Received for publication May 25, 1966.

¥ Assistant Physicians in Geriatric Medicine, Foresthall Hospital.

\$ Registrar in Geriatric Medicine, Foresthall Hospital. Now Senior Registrar, Cowley Road Hospital, Oxford.

I Chief technician, Department of Bacteriology, Stobhill General Hospital.
}

\section{Demographic Data}

Table I shows the number of males and females by quinquennial intervals. There are highly significant differences in the sub-groups between the observed and expected numbers. There are more males than expected in the seventh decade, the precise number expected in the eighth decade, and less than expected in the higher age range. The females showed a reversal of the findings for males $\left(\chi^{2}=23.16 ; n=6 ; \mathrm{P}<0.005\right)$. The mean age of males was $76 \cdot 1$ years (S.D. $= \pm 7 \cdot 51)$ and of females $77 \cdot 7$ years (S.D. $= \pm 7 \cdot 47$ ).

TABLE I

AGE AND SEX OF PATIENTS IN SERIES

\begin{tabular}{c|c|c|c|c|c|c|c|c|c}
\hline \multicolumn{2}{c|}{ Age (yrs) } & $60-64$ & $65-69$ & $70-74$ & $75-79$ & $80-84$ & $85-89$ & $\begin{array}{c}90 \\
\text { and } \\
\text { Over }\end{array}$ & Total \\
\hline Sex & $\begin{array}{l}\text { Male } \\
\text { Female }\end{array}$ & 82 & 139 & 175 & 223 & 205 & 89 & 16 & 929 \\
& 36 & 116 & 145 & 139 & 87 & 19 & 600 \\
\hline
\end{tabular}

There were far more married men $(25 \cdot 2$ per cent.) among the patients studied than married women ( 12.3 per cent.) and more widows $(65.5$ per cent.) than widowers ( 45.4 per cent.). The percentage of single men admitted ( 26.5 per cent.) was greater than the percentage $(20.5$ per cent.) of single women $\left(\chi^{2}=7 \cdot 11 ; n=1 ; \mathrm{P}<0.01\right)$. More than half of the males ( 57.6 per cent.) and a similar proportion of females $(58 \cdot 2$ per cent.) were admitted from their own homes. About one-fifth $(20.9$ per cent. of males and 19.0 per cent. of females) came from Local Authority accommodation and a similar proportion (21.4 per cent. of males and 22.9 per cent. of females) from other hospitals.

Only eighteen males and nineteen females were placed in Social Classes 1 and 2 whereas 911 males and 581 females were in Social Classes 3, 4, and 5. 
This is not unexpected in Glasgow, because trades such as shipbuilding, though skilled, are placed in the lower categories.

\section{The Survey}

A battery of standard and special serological tests for syphilis (STS) and the Gonococcal complement-fixation test (GCFT) were performed routinely on all persons admitted to the Unit irrespective of source of admission. The tests comprised the Wassermann reaction (cardiolipin, Whitechapel method), Kahn test (standard heart antigen), Venereal Diseases Research Laboratory (slide) test, Reiter Protein complement-fixation test (N.V. Organon OSS), and Price's precipitation reaction. An occasional fluorescent treponemal antibody (FTA) test was performed. A subsequent examination of the retained sera from our patients for the years 1964-5 was undertaken by the FTA Test. Generally these tests were repeated thrice at intervals of about a week when a positive result was obtained. No acute biological false positive (BFP) reaction occurred in this series though this procedure would have detected such reactors.

Table II shows the incidence of serological reactors by sex. The third column for each sex indicates those with positive results for both syphilis and gonorrhoea. Examining the results for syphilis alone reveals that there is no significant variation by age for men $\left(\chi^{2}=0.03 ; n=1\right.$;
$\mathrm{P}>0.80)$ or for women $\left(\chi^{2}=0.49 ; n=1\right.$; $P>0.30)$ or between the sexes $\left(\chi^{2}=0.19\right.$; $n=1 ; \mathrm{P}>0.50)$. The incidence for syphilis in this series by serological results is $7 \cdot 32$ per cent. for males and 6.83 per cent. for females. The incidence of positive GCFTs is $2 \cdot 79$ per cent. for males and $2 \cdot 0$ per cent for females. It is generally agreed that the GCFT is valueless in old people on account of cross-antigenicity with other Neisseria and hence no further comment will be made of the results.

Table III shows the patients with positive tests by civil status. The number "separated" is too small for comment. It is apparent that the group least involved is that of the married persons. This seeming protection for the married state does not reach statistical significance for men $\left(\chi^{2}=3 \cdot 4\right.$; $n=2 ; \quad P<0.2)$ or for women $\left(\chi^{2}=0.99\right.$; $n=2 ; \mathrm{P}>0.5)$ or by contrasting men and women $\left(\chi^{2}=0.78 ; n=1 ; P>0.3\right)$. This simply indicates that, in the past, while it was a little protection to be married, venereal disease cut across all marital status groups and involved the sexes in comparable proportions. There were some patients with positive tests for both diseases: one married male, two single males, one widowed female, two widowed males, and one separated female. The distribution of positive cases, by serology, is proportional to the civil status of the groups in the whole series with the exception of single males (33.7 per cent.) compared with single men who

TABLE II

SEROLOGICAL REACTORS, BY AGE AND SEX

\begin{tabular}{|c|c|c|c|c|c|c|c|c|c|c|c|}
\hline \multicolumn{2}{|c|}{$\begin{array}{lll}\operatorname{Sex} & \ldots & \ldots\end{array}$} & \multicolumn{5}{|c|}{ Male } & \multicolumn{5}{|c|}{ Female } \\
\hline Results & .. $\quad .$. & Syphilis & Gonorrhoea & Both & Neg. & $\begin{array}{c}\text { Total } \\
\text { Reactors }\end{array}$ & Syphilis & Gonorrhoea & Both & Neg. & $\begin{array}{c}\text { Total } \\
\text { Reactors }\end{array}$ \\
\hline $\begin{array}{l}\text { Age } \\
\text { (yrs) }\end{array}$ & $\begin{array}{l}60-64 \\
65-69 \\
70-74 \\
75-79 \\
80-84 \\
85-89 \\
90+\end{array}$ & $\begin{array}{r}2 \\
12 \\
10 \\
19 \\
12 \\
7 \\
1\end{array}$ & $\begin{array}{l}1 \\
5 \\
4 \\
4 \\
5 \\
2 \\
-\end{array}$ & $\begin{array}{l}\overline{7} \\
\frac{1}{2} \\
\frac{1}{1}\end{array}$ & $\begin{array}{r}79 \\
122 \\
160 \\
198 \\
187 \\
80 \\
14\end{array}$ & $\begin{array}{r}3 \\
17 \\
15 \\
25 \\
18 \\
9 \\
2\end{array}$ & $\begin{array}{r}2 \\
6 \\
5 \\
12 \\
12 \\
2 \\
-\end{array}$ & $\begin{array}{l}-1 \\
1 \\
3 \\
3 \\
2 \\
-\end{array}$ & $\begin{array}{l}\frac{\pi}{1} \\
=\end{array}$ & $\begin{array}{r}36 \\
48 \\
110 \\
129 \\
124 \\
83 \\
19\end{array}$ & $\begin{array}{r}2 \\
8 \\
6 \\
16 \\
15 \\
4 \\
-\end{array}$ \\
\hline & Total & 63 & 21 & 5 & 840 & 89 & 39 & 10 & 2 & 549 & 51 \\
\hline
\end{tabular}

* NEG. = Negative Serological Investigations.

TABLE III

SEROLOGICAL REACTORS, BY MARITAL STATUS AND SEX

\begin{tabular}{|c|c|c|c|c|c|c|c|c|c|c|}
\hline \multirow{2}{*}{$\begin{array}{c}\text { Marital Status } \\
\text { Sex } \quad \ldots \quad \ldots\end{array}$} & \multicolumn{2}{|c|}{ Married } & \multicolumn{2}{|c|}{ Single } & \multicolumn{2}{|c|}{ Widowed } & \multicolumn{2}{|c|}{ Separated } & \multicolumn{2}{|c|}{ Total } \\
\hline & Male & Female & Male & Female & Male & Female & Male & Female & Male & Female \\
\hline Negative & 217 & 70 & 216 & 112 & 382 & 359 & 25 & 8 & 840 & 549 \\
\hline $\begin{array}{l}\text { Syphilis } \\
\text { Gonorrhoea }\end{array}$ & $\begin{array}{c}11(5 \cdot 1 \%) \\
7\end{array}$ & $4(5 \cdot 7 \%)$ & $26(12 \cdot 0 \%)$ & $9(8 \cdot 0 \%)$ & $\begin{array}{c}30(7.9 \%) \\
12\end{array}$ & $\begin{array}{c}27(7.5 \%) \\
8\end{array}$ & 1 & $\frac{1}{2}$ & $\begin{array}{l}68 \\
26\end{array}$ & $\begin{array}{l}41 \\
12\end{array}$ \\
\hline
\end{tabular}


were uninfected (25.7 per cent.). This difference reached statistical significance $\left(\chi^{2}=8.9 ; n=2\right.$; $\mathrm{P}<0.02$ ).

Table IV shows the numbers by source and sex with negative and positive serological findings for syphilis and gonorrhoea. The numbers from each source are comparable for men and women who were negative. A significantly lower number of positive cases are admitted from home for both sexes, the number from hospital is as expected, but there is a significantly greater number of positive cases from Local Authority accommodation $\left(\chi^{2}=16 \cdot 03\right.$; $n=2 ; \mathrm{P}<0.005)$. Analysis of the distribution of syphilis alone shows an even more striking extension of the trend, clearly implicating the male $\left(\chi^{2}=\right.$ $9.279 ; n=2 ; \quad \mathrm{P}<0.01)$ compared with the female $\left(\chi^{2}=4 \cdot 296 ; n=2 ; P<0 \cdot 2\right)$. The precise significance of this fact is uncertain. It may be that some of the persons accommodated in Local Authority homes under the terms of the Acts represent a life-long problem in terms of personal inadequacy and have had difficulty in establishing normal personal relationships.

Table $\mathrm{V}$ shows some similarity between the sexes for the results of each test. Positive results were most frequently seen with the Kahn test followed by the VDRL, WR, RPCFT, and PPR in diminishing frequency. The FTA test was performed during the period of the study in two males and five females and was positive in these cases; the two males each had four other tests positive; two of the females had three other tests positive and three had four other tests positive. The three males with a positive PPR each had four other tests positive, two of the females each had four other tests positive, one female had three other tests positive, and one female had no other tests positive. The PPR has been discontinued by our laboratory.

\section{Fluorescent Treponemal Antibody Test}

The retained frozen sera of all patients over 60 years of age entering Foresthall Hospital in 1964 and 1965 (1,044 patients) were re-examined by the WR, RPCF, Kahn, VDRL, and FTA tests. The whole re-investigated series of 644 males and 400 females comprised the cases from two of the three years of our survey. It was considered that the FTA separates the true cases of syphilis from the false positive reactors, though a non-reactive FTA test is not always conclusive evidence for the absence of syphilis. The incidence of positive cases by these tests was $6 \cdot 2$ per cent. for males and $4 \cdot 3$ per cent. for females. The FTA test was positive in 3.1 per cent. of males and 1.5 per cent. of females. These figures were based on an interpretation of the tests without any clinical or epidemiological knowledge of the cases and the positive findings may well be higher.

TABLE IV

SEROLOGICAL REACTORS, BY SOURCE OF ADMISSION AND SEX

\begin{tabular}{|c|c|c|c|c|c|c|c|c|c|}
\hline \multicolumn{3}{|c|}{ Source of Admission . } & \multicolumn{2}{|c|}{ Home } & \multicolumn{2}{|c|}{ Hostel } & \multicolumn{2}{|c|}{ Hospital } & \multirow{3}{*}{$\begin{array}{r}\text { Total } \\
\begin{array}{r}549 \\
51\end{array}\end{array}$} \\
\hline & & & No. & Per cent. & No. & Per cent. & No. & Per cent. & \\
\hline \multirow{2}{*}{ Sex } & Female & $\begin{array}{l}\text { Negative } \\
\text { Positive }\end{array}$ & $\begin{array}{r}324 \\
25\end{array}$ & $\begin{array}{l}59 \cdot 0 \\
49 \cdot 0\end{array}$ & $\begin{array}{l}97 \\
17\end{array}$ & $\begin{array}{l}17 \cdot 7 \\
33 \cdot 3\end{array}$ & $\begin{array}{r}128 \\
9\end{array}$ & $\begin{array}{l}23 \cdot 3 \\
17 \cdot 7\end{array}$ & \\
\hline & Male & $\begin{array}{l}\text { Negative } \\
\text { Positve }\end{array}$ & $\begin{array}{r}494 \\
42\end{array}$ & $\begin{array}{l}58 \cdot 8 \\
47 \cdot 2\end{array}$ & $\begin{array}{r}165 \\
29\end{array}$ & $\begin{array}{l}19 \cdot 6 \\
32 \cdot 6\end{array}$ & $\begin{array}{r}181 \\
18\end{array}$ & $\begin{array}{l}21 \cdot 5 \\
20 \cdot 2\end{array}$ & $\begin{array}{r}840 \\
89\end{array}$ \\
\hline
\end{tabular}

The percentages refer to each group, negative and positive, for each sex.

TABLE V

RESULTS OF INDIVIDUAL TESTS FOR SYPHILIS AND GONORRHOEA IN 929 MALES AND 600 FEMALES

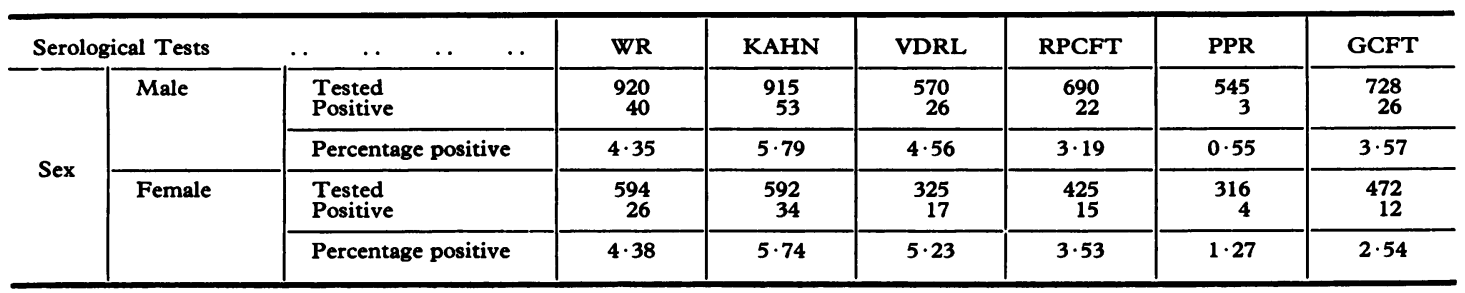


The PPR, FTA, and GCF tests are excluded from Table VI. One female had a positive PPR in isolation. Because of the possibility of BFP reactions, a Table of individual results is shown; 42 patients had three or all four tests positive and may be accepted as cases of syphilis. If 5 per cent. of BFP reactions occurred in those with two tests positive, then the loss will be statistically negligible and may be ignored as the incidence is the product of the incidence for each test. At worst the WR has shown 14 per cent. BFPs and, assuming that all our cases with single positive tests had this phenomenon, at worst the number of cases would fall by only six and the incidence is 6.89 per cent. for males and $6 \cdot 3$ per cent. for females. (Even if all cases with one test positive are excluded, the incidence remains significant at 4.09 per cent. for males and 4.33 per cent. for females.) The level of confidence in the tests performed by our laboratory is thought to be better than 97 per cent. based on multiple tests, repeated serological studies (which detect acute BFP reactors), and on titres.

\section{TABLE VI}

TOTAL TESTS POSITIVE IN INDIVIDUAL CASES (SYPHILIS), BY SEX

\begin{tabular}{|c|c|c|c|c|c|c|c|}
\hline \multicolumn{3}{|c|}{ No. of Tests Positive } & $\begin{array}{c}\text { All } \\
\text { Four }\end{array}$ & Three & Two & One & $\begin{array}{l}\text { Total } \\
\text { Cases }\end{array}$ \\
\hline \multirow[t]{3}{*}{ Sex } & \multicolumn{2}{|c|}{$\begin{array}{l}\text { Male } \\
\text { Female }\end{array}$} & 11 & $\begin{array}{l}13 \\
10\end{array}$ & $\begin{array}{r}14 \\
8\end{array}$ & $\begin{array}{l}30 \\
14\end{array}$ & $\begin{array}{l}68 \\
40\end{array}$ \\
\hline & \multirow[t]{2}{*}{ Total } & No. & 19 & 23 & 22 & 44 & \multirow[t]{2}{*}{108} \\
\hline & & Per cent. & $17 \cdot 6$ & $21 \cdot 3$ & $20 \cdot 4$ & $40 \cdot 7$ & \\
\hline
\end{tabular}

\section{Clinical Observations on the Series}

Of the 109 serologically positive cases of syphilis, only seven males and nine females had clinical evidence of disease. 85.3 per cent. showed no evidence of venereal infection. Fewer males had signs among positive cases $\left(\chi^{2}=3 \cdot 134 ; n=1 ; \mathrm{P}>\right.$ $0.05)$ though numbers are small. Three males and two females were clinically recognizable cases of syphilis, but were sero-regative. They have been excluded from all Tables. With these cases the incidence of syphilis becomes 7.6 per cent. for males and $7 \cdot 2$ per cent. for females. Four other sero-negative males admitted a history of infection. For the whole series the clinical incidence of infection may be expressed as 1.4 per cent. of 1,529 cases. No patient in Social Classes 1 or 2 showed existence of infection clinically or serologically.

Among the sero-positive males there were two cases of aortic incompetence, two of aortic aneurysm, one of tabes dorsalis, one of meningovascular syphilis, and one of general paralysis of the insane. Among the sero-negative males there were three cases of tabes dorsalis. One male had urethral stricture due to gonococcal infection.

There were four cases of aortic incompetence in sero-positive female cases, one case of meningovascular syphilis, two of tabes dorsalis, and one of "ataxia". One women had had three stillbirths in a total of eleven children and her husband died at an early age from "heart disease". Of the two seronegative females, one had amyotrophic lateral sclerosis with tabes dorsalis and one had meningovascular syphilis.

Lumbar puncture had been performed in 24 males and eight females. Six paretic curves and six tabetic curves were found. The cerebrospinal fluid was sero-positive in seven cases. A history of infection was given by only sixteen males and four females (13.3 per cent.). Treatment (mainly penicillin) had been given to 23 males and eleven females. Bismuth and neoarsphenamine had been given both in this hospital and elsewhere. Most elderly patients had been treated with incidental antibiotics at some time and this may have affected the detection of cases, so that the incidence of venereal disease may well be higher than we have detected.

\section{Autopsy Series}

A separate study was undertaken of records of 1,056 patients coming to autopsy during the years 1958-65 inclusive. Eighty were excluded as they were young chronic sick cases (under 60 years of age). There were 51 unequivocal cases of venereal disease detected by macroscopic inspection and histological confirmation, one of gonococcal arthritis, and the remainder syphilis. Most lesions were found in the cardiovascular or central nervous systems. Cardiovascular lesions were found in seventeen males (2.9 per cent.) and ten females (2.6 per cent.). Eleven males had syphilitic aneurysm, five had aortic incompetence, and one had aortitis. Two females had aneurysms, two aortic incompetence, and six aortitis. Lesions of the central nervous system occurred in sixteen males $(2 \cdot 7$ per cent.) and five females ( 1.3 per cent.). There was one gumma of bone (male) and one gumma of the pituitary (female). No case had combined lesions.

Of the clinical series of 150 sero-positive and seronegative patients, nine males and five females eventually came to autopsy. The nine males produced evidence of general paralysis of the insane 
(GPI) in one case, aortic aneurysm in another, and aortitis in three. The five females produced two cases of aortitis. Of these fourteen cases, half showed pathological features of syphilis. In 32 autopsies performed in patients over 90 years of age (14 males and 18 females) it is noteworthy that no evidence of venereal infection was found.

Thus the incidence of syphilis at post mortem was 5.8 per cent. in males and $4 \cdot 1$ per cent. in females in the series of 588 males and 388 females, lesions being found in 34 males and sixteen females. McKeown (1965) found an incidence of syphilitic aortitis in 5.5 per cent. in her series. Though aortitis is said to be uncommon in very old people, we found one case of syphilitic aortic incompetence in a female aged 88 years. Retrospectively it was impossible to state clearly the activity of the disease in the autopsy series. Only one case of gonococcal infection was found in the autopsy series, and as only one case was detected in the clinical series, the GCF test is clearly valueless for detection in elderly people.

\section{Discussion}

Serological tests for syphilis (STS) have reached a variable degree of specificity and numerous publications have compared one test to another. It is also possible to predict when a group of tests give a BFP reaction, though this depends on the tests used and the techniques of the laboratory concerned.

Rajam (1958) from Madras, in an interlaboratory comparative study, analysed the results of the VDRL, Kahn, and WR tests in both infected and uninfected people. The specificity, that is the results in uninfected healthy normal subjects, was 97.6 per cent. for the VDRL test, $97 \cdot 6$ per cent. for the Kahn test and 86.1 per cent. for the WR. The sensitivity, that is the positive results in cases of proven syphilis, was $95 \cdot 2$ per cent. for the VDRL test, 83.4 per cent. for the Kahn test, and 85.6 per cent. for the WR. This study showed the VDRL test as the best reagin test.

Patton and Gaurie (1961) compared the Kolmer and RPCF tests with the VDRL slide test. They concluded that, when all were positive, then the incidence of BFP reactors was less than 5 per cent. They further suggested that, because of this low incidence, the Reiter test could be used as a secondary screening test.

Sequeira (1962) supported this view, and reported a specificity of 99.4 per cent. for the RPCF test.

The Reiter test compared favourably with the FTA test in our series.
Putkonen, Jokinen, and Förström (1963) compared seven tests in cases of proven neurosyphilis showing that the TPI test was virtually 100 per cent. specific and that the Reiter and VDRL tests were almost as specific.

It appears, therefore, that special tests are desirable for a greater reliability of result when checking a single STS result for an individual and also to indicate possible BFP reactors. Sequeira (1962) recommended a STS and the RPCF test, with the TPI as a confirmatory test in cases of discrepancy, as the most reliable test system extant. Specific tests have now reached a high degree of specificity and sensitivity, producing between $1: 100$ and 1:1,000 BFP reactions (Sequeira, 1960).

Tomizawa, Kasamatsu, Yamaya, and Murata (1964) felt that the FTA techniques were as specific as the TPI and TPCF and were less laborious in terms of antigen preparation and performance, though Carpenter, Boak, Miller, and Le Clair (1965) found some variation in agreement with the FTA and TPI tests and recommended the latter as more dependable. Rockwell, Yobs, and Moore (1964), with a group of "untreated" cases of syphilis (96 per cent. of whom had had some therapy other than incidental antibiotics), studied the survivors (41 per cent. who had reached the age of 65 years; 66 per cent. of the group surviving had detectable reagin by the VDRL test, 91 per cent had a reactive TPI test, and 97 per cent. had a reactive FTA absorption test. The latter two tests were quite sensitive in detecting past syphilis which had passed the early stages, regardless of duration or therapy.

A BFP reaction may occur, not by technical error, in persons not infected with pathogenic treponemata in STS. It is now generally agreed that BFP reactions given by STS may be divided into two groups: "acute" and "chronic'. Hartl (1958) found 150 BFP reactors in 4,679 specimens $(3 \cdot 2$ per cent.) the majority being "acute", and only three considered to be "chronic". Putkonen (1965) used the RPCF test to find the BFP reactors, and concluded that the TPI enables the definite separation of the BFP from cases of syphilis; 70 per cent. of his BFP reactors were possible or definite cases of collagen disorders. Moore and Mohr (1952), in an important paper, list the approximate incidence of BFP reactors in various non-syphilitic conditions. The "chronic" cases were mainly leprosy and discoid or disseminated lupus erythematosus. The "acute" reactors varied from a 100 per cent. positivity in malaria, 60 per cent. in leprosy, and 30 per 
cent. in relapsing fever to 20 per cent. for rat-bite fever, vaccinia, typhus, pneumonia (atypical), lymphogranuloma venereum, disseminated lupus erythematosus, and infectious mononucleosus. A lesser incidence was found in leptospirosis (10 per cent.) and trypanosomiasis (10 per cent.). A 5 per cent. incidence occurred in sub-acute bacterial endocarditis, chancroid, scarlatina, measles, chickenpox, and rheumatoid arthritis. Advanced tuberculosis produced 3-5 per cent. BFP results and pneumococcal pneumonia $2-5$ per cent. They also felt that repeated blood donations and pregnancy could produce false positive reactions. Any elevation of serum globulin can cause BFP results. In a study of elderly people, it is apparent that few of these conditions would be found with any frequency and that a figure of 5 per cent. BFP reactors is a fair and realistic assumption, especially as repeated examinations would reveal the acute type. Deducting 5 per cent. from our positive series and adding the serologically negative but clinically recognizable cases produces an incidence of syphilis of $7.2 \mathrm{per}$ cent. for males and $6 \cdot 83$ per cent. for females.

The literature abounds in survival studies for syphilis, showing especially the lapse of time after infection when pathological change is demonstrable, but there is a paucity of work on elderly subjects as an unselected group. In one of the most important papers in the field, Collart and Durel (1964) showed that treponemata reached the cerebrospinal fluid with great rapidity and that the organisms may persist in an inactive form for the duration of the disease without necessarily producing pathological changes. It was suggested that organisms may exist as commensals which cannot be eradicated after they have been present for more than 2 years. A state of latency was felt to exist between host and parasite which coincided with apparent clinical cure though the organisms were not eradicated and bacteriological cure could not be presumed. Almost all late clinical syphilis passes through a stage of latency which often lasts for many years.

These conclusions receive clinical support from earlier work by Gjestland (1955) in his Oslo study which was derived from Boeck's original series of untreated cases of syphilis from the years 1891 to 1910. Of the patients of this cohort who died $15 \cdot 1$ per cent. of males and $8 \cdot 3$ per cent. of females showed syphilis as the primary cause of death. In the surviving group (to the years 1949 to 1951), $9 \cdot 2$ per cent. of males and $5 \cdot 1$ per cent. of females had neurosyphilis and 14.9 per cent. of males and 8.0 per cent. of females had cardiovascular syphilis. Gjestland showed that just under 70 per cent. of these patients were not inconvenienced by their disease. The average age at diagnosis of the original infection was 25.6 years for males and 24.3 years for females. If these figures are comparable, bearing in mind that penicillin was not available to the majority of our patients and that only a minority were treated, then the peak of infection lies during the 1914-18 war in our positive cases. Dencker and Nielsen (1959) studied a group of elderly subjects 552 males and 422 females living in Bornholm using the TPI and STS. These patients were selected, having been born 65 and 70 years previously. Serum was obtained from only 882 subjects and was tested by the WR, Kahn, and Meinicke tests. Sixteen cases of syphilis were detected by serological reactions, an incidence of 1.8 per cent. in this study of normal subjects. Unfortunately their study and ours are not comparable and no valid conclusion can be drawn. Our series probably represents a cohort phenomenon surviving from the first world war. This viewpoint is supported by a series of 617 cases of late syphilis from Lille, published by Huriez, Agache, and Souilliart (1962); they attribute their cases to the "epidemic" of the 1914-18 war, noting that the development of tertiary syphilis remained at a constant level. Towpik (1957), in a mass serological survey (4,500 subjects), detected 500 cases of syphilis not previously diagnosed or treated; sixteen of these $(3 \cdot 2$ per cent.) who were positive were over 66 (sic) years of age. He found clinical signs in 14 per cent. of his cases. The incidence of clinical manifestations in our series was $14 \cdot 7$ per cent.

Little is known of the sexual life of elderly people, normal or abnormal. In a series of 1,000 males and 500 females who had exposed themselves to risk and voluntarily attended Venereal Disease Clinics in Glasgow, 23 males and four females were between 60-69 years of age and seven males and one female were between 70-79 years of age. Thus 3 per cent. of males attending clinics were over 60 years of age and one per cent. of females (though the incidence may well be nearer 2 per cent. as the group was weighted by a large number of girls from remand homes) were in a similar age group. 10 per cent. of all patients attending were over 45 years of age (Schofield, 1966). Venereal diseases, therefore, provide a small but important problem in geriatric practice, remembering that not all disease is acquired in youth.

Syphilis is never infectious after it has been present for 4 to 5 years. The question of treatment may be considered irrelevant if the views of Heywood (1952) are accepted. He felt that a positive 
WR in old age was meaningless in terms of treatment and that elderly people were fortunate that they had not been "subjected to a treatment test of reversibility" which might have produced worse evils than possession of a positive test. It is, however, generally agreed that it is possible to distinguish true latency from active disease of the aorta or other viscera, which may not be clinically demonstrable, by examining the cerebrospinal fluid and the electrocardiogram and screening the aorta. Treatment must be given when positive evidence is found of pathological change, no matter what the age of the patient. A course of bismuth with potassium iodide is a wise precaution before giving penicillin; but heroic attempts to convert positive STS to negative should be avoided. The detection and interpretation of serological results in surveillance is difficult and depends upon the results of a sequence of tests over a period of time. Current opinion favours a reagin test, either the VDRL test or a quantitative WR, as the first stage in diagnosis, confirming positive results with the RPCF or FTA test. The TPI should be used in doubtful cases or to confirm other results. If active disease is shown to be present, then treatment must be given.

\section{Summary}

A battery of standard and specific tests for syphilis was performed on 1,529 elderly patients over 60 years of age. The incidence of syphilis by these tests was $6 \cdot 7$ per cent. allowing for possible biological false positive reactions. In an autopsy series of 976 subjects over 60 years of age, the incidence of syphilis was $5 \cdot 1$ per cent.

We are grateful to Prof. W. Ferguson Anderson and Dr F. A. Walkey for permission to conduct this survey and Dr R. Taylor for access to the autopsy material. The tests were performed in the Department of Bacteriology, Stobhill General Hospital, and we are grateful to Dr J. S. Stevenson [and Mr P. A. Boot, Chief Technician], for much help and valued advice. We are particularly indebted to Dr Nairn Cowan, Medical Officer of Health, Rutherglen, for statistical advice and Dr C. B. S. Schofield for criticizing the manuscript.

\section{REFERENCES}

Carpenter, C. M., Boak, R. A., Miller, J. N., and Le Clair, R. A. (1965). Calif. Med., 102, 14.

Collart, P., and Durel, P. (1964). Ann. Derm. Syph. (Paris), 91, 485.

Dencker, F., and Nielsen, H. A. (1959). Dan. med. Bull., 6,230 .

Gibson, I. I. J. M., and Pritchard, J. G. (1965). Geront. clin., 7, 330.

Gjestland, T. (1955). "The Oslo Study of Untreated Syphilis”. Acta derm.-venereol. (Stockh.), 35, Suppl. 34.

Hartl, W. (1958). Z. klin. Med., 155, 379.

Heywood, C. P. (1952). Brit. F. vener. Dis., 28, 3.

Huriez, C., Agache, P., and Souilliart, F. (1962). Bull. Soc. méd. Hôp. Paris, 113 (4 ser., 77), 466.

McKeown, F. (1965). "Pathology of the Aged", p. 73. Butterworths, London.

Moore, J. E., and Mohr, C. F. (1952).F. Amer. med. Ass., 150, 467.

Patton, R. B., and Gaurie, A. (1961). Amer. F. clin. Path., 36, 383.

Putkonen, T. (1965). Acta derm.-venereol. (Stockh.), 45, 148.

—, Jokinen, E. J., and Förström, L. (1963). Ibid., 43, 405.

Rajam, R. V. (1958). Bull. Wld Hlth Org., 19, 995.

Rockwell, D. H., Yobs, A. R., and Moore, M. Brittain (1964). Arch. intern. Med., 114, 792.

Schofield, C. B. S. (1966). Personal communication.

Sequeira, P. J. L. (1960). "Developments in the Serology of Syphilis", in "Recent Advances in Clinical Pathology", Series III, ed. S. C. Dyke, p. 58. Churchill, London.

- (1962). Brit. F. vener. Dis., 38, 9.

Tomizawa, T., Kasamatsu, S., Yamaya, S., and Murata, R. (1964). Fap. F. med. Sci. Biol., 17, 280.

Towpik, J. (1957). Brit. F. vener. Dis., 33, 2.

\section{La moralité chez les vieillards}

Une étude des tests sériques pour révéler une infection vénérienne chez les vieillards.

\section{Résumé}

Une série de tests standards et spécifiques pour la syphilis a été faite chez 1,529 malades âgés de plus de 60 ans. L'incidence de la syphilis établie par ces tests a été de 6,7 pour cent, déduction faite de la possibilité des réactions biologiques pseudo-positives. D'une série d'autopsies faites sur 976 personnes âgées de plus de 60 ans, l'incidence de la syphilis a été de 5,1 pour cent. 